\title{
A comparative study of the stability ball vs. the desk chair in healthy young adults: sagittal curvature, sitting duration and usability J Robinson*, J Bettany-Saltikov and J Warren
}

\author{
Address: University of Teesside School of Health and Social Care Borough Road Middlesbrough, TS1 3BA, UK \\ Email: J Robinson* - b1g_jon@hotmail.com \\ * Corresponding author
}

from 6th International Conference on Conservative Management of Spinal Deformities

Lyon, France. 21-23 May 2009

Published: I4 December 2009

Scoliosis 2009, 4(Suppl 2):O33 doi:I0.I I86/I748-7|6I-4-S2-O33

This abstract is available from: http://www.scoliosisjournal.com/content/4/S2/O33

(c) 2009 Robinson et al; licensee BioMed Central Ltd.

\section{Objectives}

The purpose of this study was to evaluate the effect of seating type on sitting posture through comparison of a modified desk chair and a stability ball in the sagittal plane over a duration of 30 minutes. The usability of the stability ball was assessed through the completion of a purposely designed questionnaire.

\section{Background}

Lower back pain affects a significant number of people throughout working life, meaning treatment and prevention are key topics in back care. In recent years the stability ball has increased in popularity as a common tool used in physiotherapy practice. However its uses have been taken out of the gym and into the workplace as an alternative to the traditional desk chair in an attempt to combat back pain through the belief of encouraging a better sitting position.

\section{Method}

Twenty eight subjects participated in the study, sourced from the student population of the University of Teesside. Postural information was collected using the Microscribe 3DX Digitiser from Immersion Corp Ltd. (California). A desk chair with the back rest removed was used and categorized as a stable seating type, allowing comparison to the unstable stability ball. Spinal curvature was recorded at the point of initial sitting, and through 10 minute intervals for a total of 30 minutes on each of the seating types.
A usability questionnaire was completed by each subject following each sitting trial.

\section{Results}

The results showed no significant difference with regard to spinal curvature between seating types ( $p>0.05$ ). Initial sitting curvature was found to increase significantly over 30 minutes in both the desk chair and stability ball ( $\mathrm{p}<$ $0.05)$. In addition the results of the usability questionnaire showed a significant difference in 3 of the 8 questions $(\mathrm{p}<0.05)$, in favor of the desk chair.

\section{Conclusion}

No benefits were found through sitting on a stability ball over that of a desk chair in prolonged sitting as both seating types were found to replicate a poor sitting position through a kyphosed and slumped posture. The clinical implications of this study serve to benefit any healthcare professional considering use of the stability ball as a replacement desk chair. 